\title{
Optimal Design Test Research of Pump Concrete Mix for Long Transportation Time \\ Cheng-Hua FU ${ }^{1, a}$, Huan-Min ZHANG ${ }^{2, b}$
}

${ }^{1}$ The state key laboratory of water resources and hydropower engineering science of wuhan university, Wuhan, 430072

${ }^{2}$ School of energy and environment of xihua university, China.Chengdu,610039

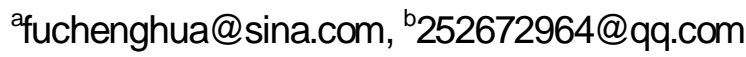

\section{Keywords: Long Transportation Time, Pump Concrete, Mix Proportion, Optimal Design.}

\begin{abstract}
Carried out the pump concrete mix optimizing tests for Jinping II diversion tunnels secondary lining by preference tests of 4 kinds of fly ash, comparison tests of 7 kinds of water reducing agent, mixing with air-entraining agent, mixing with different kinds of cement, parameters selection test of standard mix proportion, relative test of strength and water-glue ratio, etc. On base of these optimizing tests, a series of technical measures have been applied to reduce unit water consumption and cementitious material consumption of concrete, improve performances of fresh mixed concrete and hardened concrete, meet the requirements of long transportation time, and increase the economy and duration of concrete. It is a good reference for other project to solve the difficulties of pump concrete long time transporting.
\end{abstract}

\section{Introduction}

Mix proportion of pump concrete must be mainly designed to meet the technical requirements of concrete strength, and duration, workability under special conditions. The concrete must be designed with economy, good quality, and high pumping efficiency by rational selection and usage rate of materials[1,2]. Average length of four diversion tunnels of Jinping II hydropower station is about $16.7 \mathrm{~km}$, quantity of secondary lining concrete(including overfill) is around $2.7 \mathrm{M} \mathrm{m}^{3}$, the transportation time of concrete was very long.This text is introducing the research of concrete (pump concrete C30W8, C25W8, C20W8) mix optimizing tests for Jinping II diversion tunnels secondary lining by selective preference tests of 4 kinds of fly ash, comparison tests of 7 kinds of water reducing agent(WRA), mixing with different kinds of cement, parameters selection test of standard mix proportion, relative test of strength and water-glue ratio, etc. And a series of technical measures have been taken to ensure the successful applications of optimal results in real construction.

\section{Optimal Design Test}

\section{Material Optimizing Selection}

Fly Ash Selection. Concrete flowing and hardening characteristics could be improved in order to save cement and reduce project cost by using form, micro-filling and pozzolanic effects of fly ash rationally[3]. Hence, there are 4 brands of Grade II fly ash (Gui Zhou qian neng, Qu Jing fang yuan, Gan Su liang ping, Gui Zhou ming chuan) have been tested for optimizing selection. The comparison results are as follow, water demand: Gui Zhou qian neng $>$ Qu Jing fang yuan>Gan Su liang ping $>$ Gui Zhou ming chuan;water reducing effect: Gui Zhou qian neng $<$ Qu Jing fang yuan $<$ Gan Su liang ping $<$ Gui Zhou ming chuan;concrete compress strength on 7d, 28d with 20\% dosage: Qu Jing fang yuan $<$ Gui Zhou qian neng $<$ Gui Zhou ming chuan $<$ Gan Su liang ping; the results showed that unit water consumption of concrete was decreasing with water demand rate decreasing of fly ash; unit water consumption of concrete was decreasing with dosage increasing (15\%-25\%) of fly ash. Finally, Gui Zhou mingchuan Grade II fly ash was selected as mainly supplied material after carefully comparing and analyzing the factors such as supply capacity of manufactory and transportation cost.

Wra Comparative Selection. Slump keeping performance of water reducing agent in provisional mix proportion was low, and concrete setting time was too long, these situations could not meet the requirements of long time transportation and construction; meanwhile, construction efficiency and progress were affected 
because that concrete stripping time was delayed. Hence, 3 kinds of naphthalene series and 4 kinds of polycarboxylic acid water reducing agents from 3 manufactories totally 7 kinds of agents have been tested respectively on quality, matching with cement, fly ash and stone powder, and performances of concrete mix.

(1)Quality comparative analysis.Compared with polycarboxylic acid water reducing agents, the whole water reducing rates of naphthalene series water reducing agents were lower, bleeding rates were bigger, setting time was longer, and early compress strengths were higher. Total alkali and sodium sulfate contents in naphthalene series water reducing agents were much higher than polycarboxylic acid water reducing agents; total alkali content could be unfavorable to prevent or restrain the reaction between alkali aggregate in concrete, and sodium sulfate is harmful for concrete dry-wet cycle and frost assistance.

(2)Analysis on suitability with raw materials. Fig.1 shows the adaptability tests results of water reducing agents with cement, fly ash and stone powder, we see, different water reducing agents gave quite different effects on fluidity of slurry mixed with stone powder, and the effects were different with different dosages of powder. Generally, adaptability of polycarboxylic acid WRA with stone powder is better than naphthalene series WRA. When mixed with stone powder, the fluidity of slurry with polycarboxylic acid WRA was larger at beginning, and fluidity decreased more gently at later period than slurry with naphthalene series WRA, the fluidity of slurry with NOF-AS and HLC-IX water reducing agents almost had no loss after 120min, but the fluidity of slurry with naphthalene series WRA decreased rapidly after 30min, the loss was big at each time, so it means adaptability between stone powder and naphthalene series WRA is bad. Adaptabilities of 4 kinds of polycarboxylic acid WRA from good to bad are: NOF-AS,HLC-IX,JG-2H,PCA(I). Different brands of water reducing agents from different manufactories had different adaptability with stone powder.

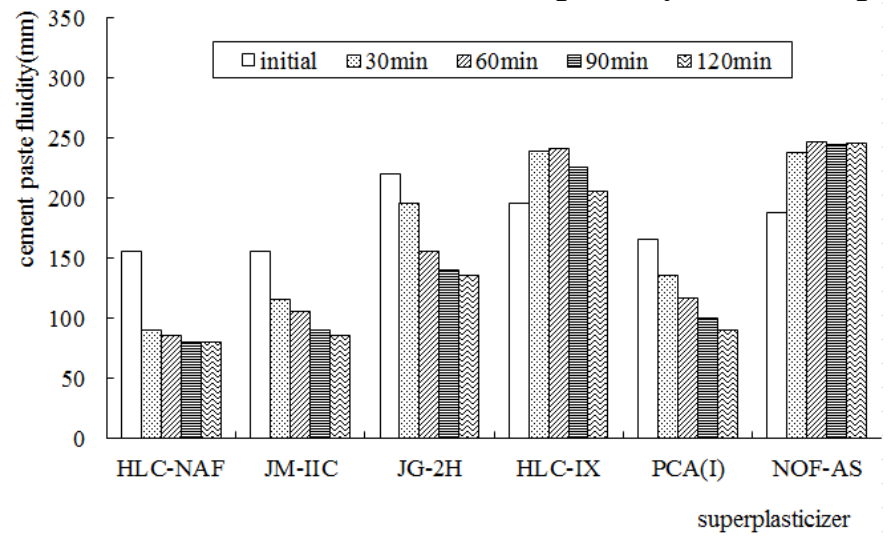

Fig. 1 Adaptabilities of Different Wra with Marble Powder

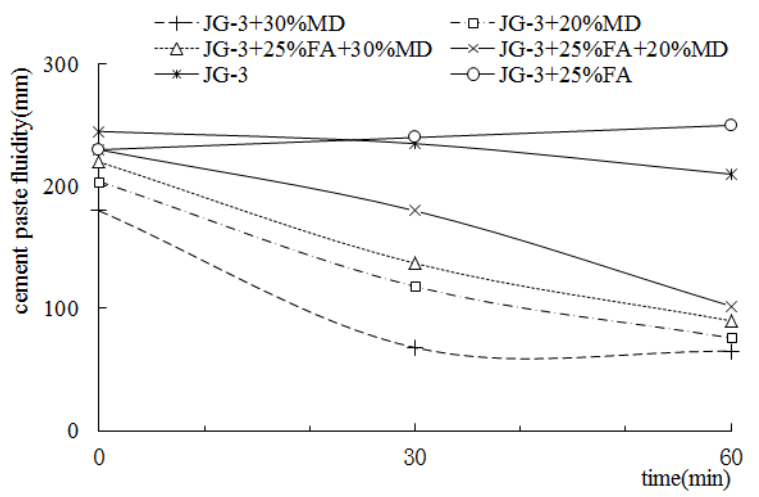

Fig. 2 Fluidity Affected by Different Dosage of Stone Powder(Fa-Fly Ash; Md-Marble Powder)

Fig.2 shows fluidity changes situation with different dosages of stone powder and mixed with stone powder and fly ash. From the chart we can see, the initial fluidity decreased when stone powder content was increased, fluidity lost quickly at later period meant powder content in sand it too high, and concrete workability would be decreased obviously. To compare stone powder with fly ash, Fly ash in mix would improve fluidity of slurry, and also retard the weakening effect on plasticity of water reducing agent by stone powder, but this retarding function would decrease with time. 
(3)Effect analysis on property of concrete mix. The contents of Table 1 are tests results of concrete performances, slump and air content losses with time when 7 kinds of water reducing agents were respectively adapted with JM-2000C(s) air entraining agent in the mix. The results show: 1) Concrete mix had bleeding by using naphthalene series WRA, but had no bleeding by using polycarboxylic acid WRA. 2) Dosage of JM-2000C(S) AEA was higher to adapt with naphthalene series WRA than adapted with polycarboxylic acid WRA. 3) Slump resistance of polycarboxylic acid WRA was obviously higher than naphthalene series WRA.

In conclusion, polycarboxylic acid WRA was better than naphthalene series WRA, therefore, polycarboxylic acid WRA was selected. In these 4 kinds of polycarboxylic acid WRAs, order of water reducing rates: NOF-AS $>$ HLC-IX $>\mathrm{JG}-2 \mathrm{H}=\mathrm{PCA}$ (I), adaptabilities with stone powder from good to bad: NOF-AS $>$ HLC-IX $>$ JG-2H $>$ PCA (I), slump losses in 1 hour from small to big: NOF-AS $<$ JG-2H $<$ HLC-IX $<$ PCA (I), mix workability from good to bad: PCA (I) $>\mathrm{JG}-2 \mathrm{H}>\mathrm{HLC}-\mathrm{IX}>\mathrm{NOF}-\mathrm{AS}$. NOF-AS and JG-2H were selected to be used in project by considering the quality and cost performance, and supply capacity and service consciousness of the manufactory.

Tab. 1 C25w8 Pump Concrete Mix Performance Tests Results with Using Different Kinds of Wra

\begin{tabular}{|c|c|c|c|c|c|c|c|c|c|c|c|c|c|c|c|c|c|}
\hline \multicolumn{3}{|c|}{ additives } & \multicolumn{15}{|c|}{ mix performances } \\
\hline \multicolumn{2}{|c|}{ WRA } & \multirow{2}{*}{$\begin{array}{l}\text { AEA } \\
\text { content } \\
\left(/ 10^{4}\right)\end{array}$} & \multirow{2}{*}{$\begin{array}{l}\text { slump } \\
(\mathrm{mm})\end{array}$} & \multirow{2}{*}{$\begin{array}{c}\text { bleed rate } \\
(\%)\end{array}$} & \multirow{2}{*}{$\begin{array}{c}\text { air } \\
\text { content } \\
(\%)\end{array}$} & \multicolumn{2}{|c|}{$\begin{array}{l}\text { set time } \\
(\mathrm{min})\end{array}$} & \multicolumn{5}{|c|}{$\begin{array}{c}\text { slump loss } \\
(\%)\end{array}$} & \multicolumn{5}{|c|}{ air content $\operatorname{loss}(\%)$} \\
\hline brand & content $(\%)$ & & & & & initial & end & Omin & $30 \mathrm{~min}$ & $60 \mathrm{~min}$ & $90 \mathrm{~min}$ & $120 \mathrm{~min}$ & $0 \mathrm{~min}$ & $30 \mathrm{~min}$ & 160min & 190min & $20 \mathrm{mir}$ \\
\hline JG-3 & 0.7 & 0.8 & 204 & 2.0 & 3.9 & 613 & 749 & 0 & 27.5 & 60.8 & 67.6 & 74.5 & 0 & 0.9 & 1.6 & 1.6 & 1.8 \\
\hline HLC-NAF & 0.7 & 0.8 & 177 & 4.3 & 3.4 & 488 & 603 & 0 & 13.6 & 40.1 & 48.0 & 63.8 & 0 & 1.3 & 1.3 & 1.7 & 1.9 \\
\hline JM- IIC & 0.65 & 0.6 & 206 & 2.4 & 5.0 & 912 & 1033 & 0 & 20.4 & 52.4 & 94.5 & 98.1 & 0 & 1.7 & 2.8 & 3.5 & 3.8 \\
\hline $\mathrm{JG}-2 \mathrm{H}$ & 0.65 & 0.6 & 185 & 0 & 3.8 & 646 & 1190 & 0 & 16.2 & 39.5 & 61.1 & 72.4 & 0 & 0.4 & 0.4 & 1.4 & 1.6 \\
\hline HLC-IX & 0.7 & 0.6 & 182 & 0 & 3.6 & 435 & 557 & 0 & 28.6 & 44.0 & 58.8 & 69.8 & 0 & 0.4 & 0.8 & 1.0 & 1.0 \\
\hline PAC(I) & 0.7 & 0.5 & 181 & 0 & 3.8 & 346 & 478 & 0 & 28.2 & 47.5 & 63.0 & 76.2 & 0 & 1.4 & 1.4 & 1.8 & 1.8 \\
\hline NOF-AS & 0.6 & 0.2 & 185 & 0 & 4.3 & 658 & 789 & 0 & 10.3 & 21.1 & 27.6 & 31.9 & 0 & 1.3 & 1.8 & 3.0 & 3.0 \\
\hline
\end{tabular}

Tab. 2 Technical Requirements of Concrete Mix

\begin{tabular}{|c|c|c|c|c|c|c|c|c|c|c|c|c|}
\hline \multirow{2}{*}{$\begin{array}{c}\text { strength level } \\
\text { of Grade II } \\
\text { concrete }\end{array}$} & \multirow{2}{*}{$\begin{array}{c}\text { max size of } \\
\text { aggregate } \\
(\mathrm{mm})\end{array}$} & \multirow{2}{*}{$\begin{array}{l}\text { strength } \\
\text { guaranteed } \\
\text { rate }(\%)\end{array}$} & \multirow{2}{*}{$\begin{array}{l}\text { probability } \\
\text { coefficientt }\end{array}$} & \multirow{2}{*}{$\begin{array}{c}\text { design limited } \\
\text { water-glue } \\
\text { ratio }\end{array}$} & \multirow{2}{*}{$\begin{array}{c}\text { strength } \\
\text { standard } \\
\text { deviation( } \mathrm{MPa} \\
\text { ) }\end{array}$} & \multirow{2}{*}{$\begin{array}{c}\text { preparation } \\
\text { strength } \\
(\mathrm{MPa})\end{array}$} & \multirow{2}{*}{$\begin{array}{l}\text { slump } \\
(\mathrm{mm})\end{array}$} & \multirow{2}{*}{$\begin{array}{c}\text { air } \\
\text { content } \\
(\%)\end{array}$} & \multicolumn{2}{|c|}{ set time(h) } & \multicolumn{2}{|c|}{ slump loss $(\%)$} \\
\hline & & & & & & & & & initial & final & $60 \mathrm{~min}$ & $120 \mathrm{~min}$ \\
\hline C20W8 & & & & & 4.0 & 26.6 & & & & & & \\
\hline C25W8 & 40 & $\geqslant 95$ & 1.65 & $\leqslant 0.55$ & 4.0 & 31.6 & $\begin{array}{c}100-18 \\
0\end{array}$ & $3-5$ & $7-9$ & $10-14$ & $\leqslant 25$ & $\leqslant 30$ \\
\hline C30W8 & & & & & 4.5 & 37.4 & & & & & & \\
\hline
\end{tabular}

\section{Cement Brand Change}

The main work at project beginning was diversion tunnel excavation and supporting, application amount of shotcrete was quite big; the high early strength of concrete was requested in order to take supporting effect promptly, hence, the cement was early strength type (P.O42.5R). This type of cement was still used for secondary lining early construction; this cement caused too fast hydration and slump loss, so the fresh mixed concrete of secondary lining pumping could not meet the requirement for long term transportation. Therefore, ordinary Portland cement (P.O42.5) was selected to be used in optimal mix proportion.

\section{Parameters Selection of Standard Mix}

Contents of table 2 are concrete design and construction technical requirements. Standard mix proportions have to be made according to technical requirements, the parameters such as: fly ash content, dosages of additives, standard water-cement ratio, unit water demand and cementitious materials contents, and optimal sand ratio and coarse aggregates combination ratio must be determined under the principle to ensure the good working performance of concrete[4,5].

Fly Ash Content Determining. Generally, fly ash content in each project was controlled between $15 \%-35 \%$, hence, fly ash content in this project was determined about $20 \%$ initially based on the optimal tests 
results, but the concrete compressive strength of site sample had too much margin, so the final optimal content was determined as $25 \%$.

Coarse Aggregates Optimal Rates Combination Determining. The optimal combination ratio of coarse aggregates could improve aggregates grading, decrease combined void volume, save mortar, and increase concrete compactness. In this considering, combined aggregates close packing density and its void volume tests of 5 combined ratios of middle and small size stones had been carried out, the difference of tests results of different combination ratios were very small. Actual ratio of middle and small stones was determined as 40:60 to ensure smooth pumping and avoid pipeline blockage.

Sand Ratio and Additives Dosage Determining. Trial mixing with 0.6 water-glue ratio has been done in laboratory in order to determine the optimal sand ratio and AEA dosage under standard water-glue ratio (tests results see table 3), unit water demand was controlled in conditions that water-glue ratio was no change and concrete slump met the design requirement.

Tab. 3 Unit Water Consumption, Additives Dosage and Sand Ratio Initial Determining with 0.60 Water-Glue Ratio

\begin{tabular}{|c|c|c|c|c|c|c|c|c|c|}
\hline \multirow{2}{*}{$\begin{array}{l}\text { unit water } \\
\text { consumption } \\
\left(\mathrm{kg} / \mathrm{m}^{3}\right)\end{array}$} & \multicolumn{2}{|c|}{ additives } & \multirow{2}{*}{$\begin{array}{c}\text { sand ratio } \\
(\%)\end{array}$} & \multirow{2}{*}{$\begin{array}{c}\text { air content } \\
(\%)\end{array}$} & \multirow{2}{*}{$\begin{array}{l}\text { slump } \\
(\mathrm{mm})\end{array}$} & \multicolumn{4}{|c|}{ workability } \\
\hline & $\begin{array}{c}\text { WRA } \\
(\%)\end{array}$ & $\begin{array}{l}\text { AEA } \\
\left(/ 10^{4}\right)\end{array}$ & & & & with sand & $\begin{array}{c}\text { stick } \\
\text { degree }\end{array}$ & cohesiveness & bleed \\
\hline 140 & 0.7 & 0.4 & 42 & 0.9 & 61 & medium & inferior & good & no \\
\hline 142 & 0.7 & 0.5 & 44 & 2.6 & 84 & medium & medium & good & no \\
\hline 144 & 0.7 & 0.6 & 43 & 4.5 & 132 & medium & medium & good & no \\
\hline 148 & 0.7 & 0.5 & 43 & 3.7 & 182 & medium & medium & good & no \\
\hline
\end{tabular}

\section{Relations of Strength and Water-glue Ratio}

Parameters of mix proportion such as: water demand, sand ratio, additives dosages, fly ash brand and content, and combined ratio of grade II coarse aggregates had been determined when standard water-glue ratio was 0.6 , then relation tests between strength and water-glue ratio of grade II pump concrete have been done respectively with 5 different water-glue ratios (were $0.40,0.45,0.50,0.55$ and 0.60 ) under the condition of same water demand. Relations between compressive strength and water-glue ratio in table 4 and table 5 were calculated by the tests results, the water-glue ratio and optimal mix proportion were determined hereby. Fluctuation of cement strength in project was quite big, the range was $(14 \pm 4) \mathrm{MPa}$, so the recommended water-glue ratio was little bit lower than calculated water-glue ratio that the concrete design and construction requirement could be satisfied when big fluctuation of cement and materials happened.

Tab. 4 Relations between Compressive Strength and Water-glue Ratio

\begin{tabular}{|c|c|c|c|c|c|c|c|c|c|c|}
\hline \multirow{2}{*}{ concrete } & \multirow{2}{*}{ cement } & \multirow{2}{*}{ age } & \multirow{2}{*}{$\begin{array}{l}\text { relation between compressive } \\
\text { strength and water-glue ratio }\end{array}$} & \multirow{2}{*}{ relative coefficient $r$} & \multicolumn{3}{|c|}{ calculated water-glue ratio } & \multicolumn{3}{|c|}{$\begin{array}{c}\text { recommended } \\
\text { water-glue ratio }\end{array}$} \\
\hline & & & & & $\mathrm{C} 20$ & $\mathrm{C} 25$ & $\mathrm{C} 30$ & $\mathrm{C} 20$ & $\mathrm{C} 25$ & C30 \\
\hline \multirow{3}{*}{$\begin{array}{c}\text { Grade II } \\
\text { pump } \\
\text { concrete }\end{array}$} & \multirow{3}{*}{$\begin{array}{c}\text { Nai tuo } \\
\text { OPC }\end{array}$} & 7 & $\mathrm{R}_{7}=18.031(\mathrm{C}+\mathrm{F}) / \mathrm{W}-14.270$ & 0.9900 & \multirow{3}{*}{0.53} & \multirow{3}{*}{0.48} & \multirow{3}{*}{0.43} & \multirow{3}{*}{0.51} & \multirow{3}{*}{0.46} & \multirow{3}{*}{0.41} \\
\hline & & 28 & $\mathrm{R}_{28}=24.956(\mathrm{C}+\mathrm{F}) / \mathrm{W}-20.345$ & 0.9957 & & & & & & \\
\hline & & 90 & $\mathrm{R}_{90}=25.1(\mathrm{C}+\mathrm{F}) / \mathrm{W}-12.659$ & 0.9900 & & & & & & \\
\hline
\end{tabular}

Tab. 5 Recommended Optimal Mix and Concrete Performance

\begin{tabular}{|c|c|c|c|c|c|c|c|c|c|c|c|c|c|c|c|c|c|c|c|}
\hline \multirow{2}{*}{$\begin{array}{l}\text { strength } \\
\text { grade }\end{array}$} & \multirow{2}{*}{$\begin{array}{c}\text { mat } \\
\text { erial } \\
\mathrm{s}\end{array}$} & \multirow{2}{*}{$\begin{array}{l}\text { water- } \\
\text { glue } \\
\text { ratio }\end{array}$} & \multirow{2}{*}{$\begin{array}{l}\text { sand } \\
\text { ratio } \\
(\%)\end{array}$} & \multirow{2}{*}{$\begin{array}{l}\text { fly } \\
\text { ash } \\
\text { cont } \\
\text { ent } \\
(\%)\end{array}$} & \multirow{2}{*}{$\begin{array}{c}\text { WRA } \\
\text { content } \\
(\%)\end{array}$} & \multirow{2}{*}{$\begin{array}{c}\text { AEA } \\
\text { content } \\
\left(/ 10^{4}\right)\end{array}$} & \multicolumn{6}{|c|}{$\begin{array}{l}\text { material quantity per each } \\
\text { cube concrete }\left(\mathrm{kg} / \mathrm{m}^{3}\right)\end{array}$} & \multirow{2}{*}{ - } & \multirow{2}{*}{$\begin{array}{l}\text { air } \\
\text { content } \\
(\%)\end{array}$} & \multicolumn{3}{|c|}{$\begin{array}{l}\text { compressive } \\
\text { strength } \\
\text { (MPa) }\end{array}$} & \multicolumn{2}{|c|}{$\begin{array}{c}\text { Split } \\
\text { tensile } \\
\text { strength }(\mathrm{MPa} \\
\end{array}$} \\
\hline & & & & & & & water & cement & $\begin{array}{l}\text { Fly } \\
\text { ash }\end{array}$ & sand & $\begin{array}{l}\text { small } \\
\text { stone }\end{array}$ & $\begin{array}{l}\text { middle } \\
\text { stone }\end{array}$ & & & $7 d$ & $28 \mathrm{~d}$ & $90 \mathrm{~d}$ & $28 \mathrm{~d}$ & $90 \mathrm{~d}$ \\
\hline C20W8 & Nai & 0.51 & 42 & & 0.60 & 0.40 & 144 & 212 & 71 & 828 & 689 & 461 & 171 & 5.2 & 19.1 & 26.9 & 33.9 & 2.39 & 2.54 \\
\hline $\mathrm{C} 25 \mathrm{~W} 8$ & tuo & 0.46 & 41 & & 0.70 & 0.30 & 144 & 235 & 78 & 797 & 690 & 462 & 190 & 3.8 & 24.8 & 34.3 & 41.4 & 2.67 & 2.79 \\
\hline C30W8 & $\begin{array}{c}\text { C } \\
\text { JG- } \\
2 \mathrm{H}\end{array}$ & 0.41 & 40 & 25 & 0.70 & 0.30 & 144 & 263 & 88 & 763 & 689 & 461 & 184 & 4.3 & 29.6 & 41.4 & 47.6 & 3.22 & 3.35 \\
\hline
\end{tabular}




\section{Optimizing Results Analysis}

Mechanical properties of hardened concrete were more rational after optimizing mix proportion (such as: Max compressive strength of $\mathrm{C} 25 \mathrm{~W} 8$ concrete in 28 days was decreased from $61.2 \mathrm{MPa}$ to $44.8 \mathrm{MPa}$ ), Max penetration height of C25W8 concrete was decreased from $12 \mathrm{~cm}-14 \mathrm{~cm}$ to $2 \mathrm{~cm}-4 \mathrm{~cm}$ under W9 permeability pressure, margin of anti-permeability was increased obviously, frost resistance was increased from less than F50 to the limitation F250.

After optimizing, cementitious materials quantities of C30W8, C25W8 and C20W8 pump concrete per cube were: $344 \mathrm{~kg}, 306 \mathrm{~kg}, 277 \mathrm{~kg}$, cementitious materials were respectively decreased: $83 \mathrm{~kg} / \mathrm{m}^{3}, 65 \mathrm{~kg} / \mathrm{m}^{3}$, $58 \mathrm{~kg} / \mathrm{m}^{3}$ to compare with original mix proportion, water demands were respectively decreased: $41 \mathrm{~kg} / \mathrm{m}^{3}$, $31 \mathrm{~kg} / \mathrm{m}^{3}, 30 \mathrm{~kg} / \mathrm{m}^{3}$, it greatly decreased amount of cementitious materials, saved cost of project, and also decreased crack risk by the advantage in concrete temperature control.

Concrete workability was improved; slump resistance could meet long time transportation and construction requirements. Hardening mechanical properties of concrete were more rational, durability was improved obviously.

\section{Conclusions}

Mix proportion aimed at design and construction technical requirements of long time transporting pump concrete for JP II diversion tunnels has been optimized by fly ash selecting, WRA comparing and selecting , dosages of WRA and AEA adjusting, and parameters adjusting. Project cost was saved, concrete workability and hardenability was improved, slump resistance could meet the requirements of long time transportation and construction, and concrete duration was obviously increased hereby. After optimal mix proportion was applied, the problem of concrete fast slump loss was well solved by WRA formulation adjusting. It is a good reference for other project to solve the difficulties of pump concrete long time transporting.

\section{Acknowledgement}

This research was financially supported by key laboratory of fluid and power machinery of education ministry in xihua university (SBZDPY-11-9).and state key laboratory of water resources and hydropower engineering science of wuhan university(2011B087).

\section{References}

[1]Wen-yao Chen, Wen-wei Li, Technology measures on mix design for dam concrete of high performance in three gorges project. Journal of Hydraulic Engineering, 31(2000)49-53.

[2]Chao-dong Cui, Quality control and key technique of the pump concrete constuction. construction technology, 35(2006)21-23.

[3]Yong-yan Zhen. Application of Fly Ash in hydraulic concrete. Water Power Press(1992).

[4]DL/T5330-2005, Hydraulic concrete mix design specifications, China Waterpower Press(2005).

[5]SL352-2006, Testing procedures for Hydraulic concrete, China Waterpower Press(2006). 